\title{
FULL LENGTH RESEARCH ARTICLE \\ CARBON CAPTURE AND STORAGE (CCS) IN NIGERIA: FUNDAMENTAL SCIENCE AND POTENTIAL IMPLEMENTATION RISKS
}

\author{
${ }^{*}$ GALADIMA, A. ${ }^{1}$ \& GARBA, Z. N. ${ }^{2}$ \\ ${ }^{1}$ Department of Pure and Applied Chemistry \\ Usmanu Danfodiyo University, P.M.B. 2346, Sokoto, Nigeria \\ ${ }^{2}$ Department of Chemistry \\ Ahmadu Bello University, P.M.B. 1044, Zaria, Nigeria \\ *(Corresponding author) \\ ahmadgldm@yahoo.com
}

\begin{abstract}
Carbon dioxide Capture and Storage (CCS) is a novel global technology encompassing the isolation and transportation of $\mathrm{CO}_{2}$ from emission points followed by storage in appropriate geological formations. Although the process had been projected to play a great role in enhancing oil recovery from partly depleted oil and gas reservoirs as well as mitigating global climate change by 2030, the science, technology, and potential consequences of its application are not well understood in many African countries like Nigeria that are majorly dependent on oil and gas economy and contributing emitters of greenhouse gases. This paper described the fundamental science of CCS and addressed the potential risks of its future implementation in Nigeria. Critical analysis of the country's oil and gas activities coupled with economic and political situation indicates that CCS project in Nigeria would be faced with challenges such as long implementation time, inefficient technology, gas leakage from geological storage, capture and storage costs and implementation decision and strategies.
\end{abstract}

Key words: Carbon, capture, storage, implementation, problems.

\section{INTRODUCTION}

The entire world is experiencing negative changes in the physical, biological and human systems. The levels of sea, ice and snow cover had decreased by about $15 \%$ and the world is becoming warmer with an overall increase in the spread of diseases, emergence of drought and exposure of fertile soil to desertification (Rosenzweig \& Casassa 2007). These are generally associated with increase in the emissions of greenhouse gases like carbon dioxide $\left(\mathrm{CO}_{2}\right)$, methane $\left(\mathrm{CH}_{4}\right)$, water vapour $\left(\mathrm{H}_{2} \mathrm{O}(\mathrm{g})\right.$ ), nitrous oxide, halocarbons and others. Carbon dioxide $\left(\mathrm{CO}_{2}\right)$ has been recognised as the most important anthropogenic greenhouse gas with an annual emission growth rate of about 80\% (IPCC 2007; Lewis 2007) and current atmospheric concentration of about 750 Giga tonnes. Various studies showed that the emitted $\mathrm{CO}_{2}$ will remain in the atmosphere for hundred of years (Lewis 2007; GF 2008). The major global concern is how further emissions can be mitigated in a manner of commercial and environmental benefits. Response from oil and gas industries being the major emitters indicate that the gas could be captured and used for tertiary oil and/or gas recovery from partly depleted reservoirs (Herzog et al. 1997; Herzog 2004; Svensson et al. 2004; GF 2008). To achieve this goal, the new sequestration technology "Carbon Capture and Storage (CCS)" will play an important future role. The process involved separation and capturing of $\mathrm{CO}_{2}$ from emission points, its transportation and storage in the subsurface. Already, so much study have been conducted in the industrialised nations on the implication of its practicalisation (Herzog 2001; Dooley 2006; IEA 2006; Irons et al. 2007) but no studies have been conducted in African countries.

Although Nigeria is the world's biggest gas flarer and largest source of $\mathrm{CO}_{2}$ emissions from Sub-Saharan Africa (EIA, 2005; Malumfashi, 2007; Ikeme, 2008), the concept of CCS is not fully understood and there is limited concern from both research and government perspectives.
This paper is aimed at highlighting the fundamental science of the process and the potential risks of its future implementation in Nigeria for the benefits of our citizens. Thus, the paper will address the questions; what is carbon capture and storage and what are the potential problems of its future implementation in Nigeria, considering our economic, political and technological status.

\section{WHAT IS CARBON CAPTURE AND STORAGE (CSS)?}

Carbon Capture and Storage (CCS) is considered by many scholars as the separation of $\mathrm{CO}_{2}$ and its capture from mixture of emitted combustion gases, followed by transportation and appropriate storage under the ground, thereby preventing it from entering the atmosphere (Herzog 1997; Ha-Doung \& Keith 2003; Anderson \& Newell 2003). CCS will best be applied to large stationary emission points like industrial plants and fossil fuels power stations, where $\mathrm{CO}_{2}$ is emitted in large quantities and can be isolated from the emitted flue gases at some important stages. The process will play a significant future role of climate change mitigation if the storage can last for hundred of years. Similarly, the captured gas can be injected into partially depleted or less productive oil and gas reservoirs to improve recovery (Williams et al. 2006; Dooley et al. 2006). In the Permian Basin of Texas United States, Carbon dioxide has been injected into over 11,000 oil wells for tertiary recovery since late 1970's and the process already accounted for over $15 \%$ of annual oil production in the region (Heller \& Taber 1986; Gozal et al. 2005; Williams et al. 2006). It has also been used for similar process in North Sea of United Kingdom. CCS involved three broad stages each of significant scientific, technological, environmental and economic concerns.

\section{Step I: $\mathrm{CO}_{2}$ Capture}

The emitted carbon dioxide can be separated and captured from mixture of flue gases by a number of projected methods normally classified as Post combustion, Pre-combustion and Oxy-combustion. 
Post combustion method uses a physical, chemical or intermediate solvent which can effectively interact with $\mathrm{CO}_{2}$, stable under desired conditions of temperature and pressure and can easily be regenerated during the process. The chemical solvents called Alkanolamines used industrially for natural gas sweetening are considered the most likely option for the current world. These solvents show limited dependency on partial pressure of $\mathrm{CO}_{2}$, which is normally $15 \%$ by volume. The aqueous solutions of these chemicals react with excess $\mathrm{CO}_{2}$ to form quaternary Nitrogen carbonate, which on heating in the reaction chamber dissociates to release the gas for transportation and the solvents regenerated.

1) $2 \mathrm{RNH}_{2}+\mathrm{CO}_{2}+\mathrm{H}_{2} \mathrm{O} \longrightarrow\left(\mathrm{RNH}_{3}\right)_{2} \mathrm{CO}_{3}$

2) $\left(\mathrm{RNH}_{3}\right)_{2} \mathrm{CO}_{3}+\mathrm{H}_{2} \mathrm{O}+\mathrm{CO}_{2} \longrightarrow 2 \mathrm{RNH}_{3} \mathrm{HCO}_{3}$

3) $2 \mathrm{RNH}_{3} \mathrm{HCO}_{3} \longrightarrow 2 \mathrm{RNH}_{2}+2 \mathrm{H}_{2} \mathrm{O}+2 \mathrm{CO}_{2}$ [Amines regeneration and carbon dioxide release for transportation to appropriate geological storage unit]. Alternatively, the process can obey the following mechanism

$2 \mathrm{RNH}_{2}+\mathrm{CO}_{2} \longrightarrow \mathrm{RNHCOONH}_{3} \mathrm{R} \longrightarrow 2 \mathrm{RNH}_{2}+\mathrm{CO}_{2}$

The compounds can be primary, secondary or tertiary alkanolmines. Table 1 presents a list of those with potentials for this application.

TABLE 1. LIST OF SOME COMMON ALKANOLAMINES FOR POTENTIAL USED IN CCS

\begin{tabular}{l|l|l}
\hline Name of chemical & Abbreviation & Scientific formula \\
\hline Monoethanolamine & MEA & $\mathrm{HOC}_{2} \mathrm{H}_{4} \mathrm{NH}_{2}$ \\
\hline Methyldiethanolamine & MDEA & $\left(\mathrm{HOC}_{2} \mathrm{H}_{4}\right)_{2} \mathrm{NCH}_{3}$ \\
\hline Diethanolamine & DEA & $\left(\mathrm{HOC}_{2} \mathrm{H}_{4}\right)_{2} \mathrm{NH}$ \\
\hline Triethanolamine & TEA & $\left(\mathrm{HOC}_{2} \mathrm{H}_{4}\right)_{3} \mathrm{~N}$ \\
\hline Di-isopropanolamine & DIPA & $\left(\mathrm{i}-\mathrm{HOC}_{2} \mathrm{H}_{6}\right)_{2} \mathrm{NH}$ \\
\hline
\end{tabular}

TEA may have limited use due to low stability and effectiveness. However, compound like MEA will be good solvent due to its vigorous reactivity with acidic gases, appreciable stability and effectiveness at lower concentrations. But selectivity may be a problem. To avoid corrosion problems and high regeneration temperature MDEA can be employed.

Pre-combustion technique involved the reaction of the fuel with (e.g. methane) with pure air or oxygen to yield a product that contains carbon monoxide (CO) and hydrogen gas, which on further reaction with steam can produce a mixture of $\mathrm{H}_{2}$ and $\mathrm{CO}_{2}$. However, some researchers believed that the process can be achieved in a single step given below.

$\mathrm{CH}_{4}+\mathrm{O}_{2} \longrightarrow \mathrm{CO}_{2}+2 \mathrm{H}_{2}$

By effective treatment the hydrogen gas can be isolated and used as fuel in a gas turbine combined cycle. Contrary to the post combustion method, this process will employ the used of physical solvent called Selexol polymeric ether).

\section{$\mathrm{CH}_{3}\left(\mathrm{CH}_{2} \mathrm{CH}_{2} \mathrm{O}\right)_{n} \mathrm{CH}_{3}$ Selexol}

The solvent reacts effectively with both $\mathrm{CO}_{2}$ and stream of Sulphur compounds, therefore up to $85-90 \%$ capture can be achieved. However, dry condition is required to mitigate corrosion problems.
The second capture method would be an important option for natural gas or coal based plants.

Oxy-combustion on the other hand is the term used when the fuel is burnt with oxygen of very high purity $(\geq 90 \%)$ and recycled flue gas or carbon dioxide and steam mixture to produce flue gas containing principally water vapour and $\mathrm{CO}_{2}$ gas. The low Nitrogen concentration of the flue gas when air is used for combustion enhanced the prospective application of the method, since further downstream treatment of $\mathrm{CO}_{2}$ is not required. Steam conditions and initial quantities of oxygen required are similar to those set for previous technique but research show that the method is at early stage of practise in developed countries like Europe.

\section{Step II: $\mathrm{CO}_{2}$ Transportation}

After the gas has been isolated and captured by any of the earlier techniques from the emission point, it must be transported to the appropriate storage location(s). The process requires both economic and technological efforts and large scale infrastructure due to the large volumes of the gas involved (Svensson et al. 2004). Concentrated amounts of $\mathrm{CO}_{2}$ can be transported through high pressure pipelines to the storage site. This had been the transport option in the Permian Basin Texas U.S.A, where the gas is injected into low producing geological reservoirs for enhanced oil recovery since the last four decades. Pipelines transportation is considered the most appropriate option for the current generation since very few accidents and risks were recorded from past decades.

Another transport option is by liquidifying the captured $\mathrm{CO}_{2}$ just like Liquidified Petroleum Gas (LPG) followed by transportation through ships, road tankers or rail cars. Technical transportation by road tankers and/or rail cars must be carried out in insulated tanks at values of temperature and pressure lower than those required for pipelines (i.e. $-20^{\circ} \mathrm{C}$ and $2 \mathrm{MPa}$ ). However, studies indicate that this system can only be suitable for very small scale application (GF 2008). Another major challenge is that up to now storage has not been practised offshore and most suitable phase conditions are not fully evaluated.

\section{Step III: $\mathrm{CO}_{2}$ Storage}

Following the separation, capture and transportation processes, the gas must be stored permanently for complete isolation from the atmosphere. Herzog (2001) and Herzog \& Golomb (2004) identified the following key factors that are necessary for an effective storage option.

-The storage should be for a very long period of time, preferably 1000 years.

-The costs of transport and storage should be minimised

-All potential risks and accidents should be identified and eliminated -Environmental impacts should be taken into account and

-The storage option should be in accordance with all national and international laws and regulations.

Several geological options are available for storage taken into accounts these factors. Results of the research by United Nation Society for Geological Survey (USGS 2000) categorised the world basins into; highly prospective basins (with adequate reservoirs, seals and traps), prospective basins which are minor, less effective basins and non-prospective basins that are highly deformed, containing basement complex rocks and therefore unsuitable for $\mathrm{CO}_{2}$ storage. 
The survey identified oil and gas reservoirs, Enhanced Oil Recovery (EOR), deep saline formations, deep unmineable coal seems, $\mathrm{CO}_{2-}$ driven enhanced coal bed methane recovery and deep saline basalts formations as the major depleted geological storage options (Dooley 2006). Depleted oil and gas reservoirs are the most appropriate land storage option in the current situation because of their good potentials to store highly pressurised fluids for very long period of time (Herzog et al. 1997). Some studies revealed that the quantity of $\mathrm{CO}_{2}$ that can be used for EOR and related applications is low compared to the total emissions level. Trillion cubic feet of coal bed methane are available worldwide. In U.S A. Alone there is over 645 trillion cubic feet. For this reason, enhance methane recovery from coal bed would be a good future option. Deep saline formations are heterogeneous structures in the sub-surface, with varying porosity and permeability distributions. If $\mathrm{CO}_{2}$ is injected into these formations, the increased perplexing in the formations and reduced reservoir permeability may inhibit the potential leak of the gas (Flett et al. 2004). These structures will therefore provide a good storage option for very long time, more importantly if the formations can react with the gas to form carbonate rocks like dolomite.

\section{WHAT ARE THE POTENTIAL RISKS OF IMPLEMENTING CARBON CAPTURE AND STORAGE (CCS) IN NIGERIA?}

In Nigeria, increasing urban and rural populations, income levels, and energy use are leading to steady increase in greenhouse gases emissions. The country has a proven reserve of 36.22 billion barrels of oil and about 180 trillion cubic feet of gas, in addition to a massive coal deposits, and an increasing primary energy consumption of about 0.9 to 1.2 Quadrillion Btu between 2003 and 2007 (EIA 2007), indicating that the emission of these gases will remain elevated for long period. Major concern here is, CCS will require future attention in Nigeria as in other developing countries like China, India and South Africa, but the potential implementation problems should be identified and addressed ahead of time. These risks varied and ranged from country to another.

In Nigeria, the economic, environmental and political situations are the consequent generators of the following potential challenges.

\section{Technology}

Though there is special interest in many countries for a shift towards low-carbon energy sources (more importantly biofuels), most projections show that the current environmentally undesirable and non-renewable fossil fuels will continue to play a significant role in the medium term (Watson et al. 2007). For example coal demand alone would increase to 4215 and 5647 million tonnes for developing countries by 2015 and 2030 respectively (IEA 2006). To ensure effective capture of $\mathrm{CO}_{2}$ that will be emitted in line with the combustion of these fuels, an efficient technology is required. For successful "Clean Coal Technology" alone, a range of modern technologies that are currently not available in developing countries like Nigeria are certainly required. These technologies will cover the preparation of coal (washing and briquetting), combustion for example by fludised bed boilers and gasification, and clean-up of undesirable gases by processes like flue gas desulphurisation and denitrification before the ultimate carbon capture and storage (Watson et al. 2007). In fact the whole CCS process involved series of advance technologies, few of which are under early stages of practise in some industrialised countries like United Kingdom and U.S.A. This clearly indicates that inefficient technology will lead to a serious setback in implementing CCS in Nigeria and most developing countries, who do not have enough technology to provide their citizens with basic amenities like pure water and electricity.
Nigeria in particular is faced with technology challenges of providing the country with up to 10,000 Mega watts power supply, which resulted to liquidation of many companies and loss of jobs. Another concern is that potential geological formations for $\mathrm{CO}_{2}$ storage in Nigeria are offshore reservoirs, and $\mathrm{CO}_{2}$ transportation technology for offshore locations has not been practicalised. In the Permian Basin where the transport was fully studied since the late 1980's, onshore pipelines are used in conveying the gas to the appropriate locations (Heller 1986; Gozal et al. 2005).

\section{Leakage}

Many studies show that the natural underground geological formations can provide adequate carbon dioxide storage for a very long period of time (Ha-Doung \& Keith 2003). However, interaction of the acidic gas with the formation and its stored resources can pose serious environmental consequences. Considering the nature of storage options in Nigeria, there would be high possibility of leakage due to low storage capacity formations, inappropriate geological traps and/or low density seals that can allow the escape of the gas. Increased environmental concentration of $\mathrm{CO}_{2}$ can lead to acidification of groundwater and soils, killing various plant and animal species and consequently altering soil fertility. In a country where the local populations depend on agriculture for food, this can reduce the possible farm outputs, causing more destructions than benefits.

\section{Capture and Storage Costs}

The costs of capture, transport and storage of $\mathrm{CO}_{2}$ depend on the country, technology and fuel types (Kallbekken \& Torvanger 2004). For example, the cost of capture from coal power plants will be higher than from gas-fired power plants due to larger concentration of the gas. Similarly transportation cost varies with applicable options. Ship and pipelines are the most potential transport options in Nigeria. Various cost estimates were reported by different authors. Analysis by Anderson \& Newell (2003) estimated total transport and storage costs of $\$ 7$ to $\$ 19$ per $1000 \mathrm{Kg}$ of $\mathrm{CO}_{2}$ while Hendriks et al. (2000) reported $\$ 13$ to $\$ 44$ per $1000 \mathrm{Kg}$ of the gas. Both authors assumed $1000 \mathrm{~km}$ transportation distance, indicating that for longer distance both transportation cost and risk of corrosion will increase (especially for offshore pipelines). In Nigeria, the costs are much likely to be higher due to metocean conditions, requiring advance pipelines technology and potentially longer transportation distance. This can seriously affect its implementation except otherwise if oil and gas companies make use of the gas in enhanced oil recovery (EOR) or be forced by the government. The consequence will be increased in oil and gas consumers cost and when this is coupled with the current poverty situation the masses would be at serious disadvantages.

\section{Decision and Regulatory Strategies}

To implement CCS successfully in Nigeria, the major emitters (oil and gas companies) and other companies permitted by the government to be involved in power distributions and related services, and other industry participants must develop the right approach that incorporates important solutions and previous lessons from international sectors like the natural gas company of America (Mandil 2005). This should include development of government regulatory frame works that ensure unconditional commitment and national support. Considering our current environmental policies that do not address this issue, its implementation will be stuck along the way if the government do not either introduce a new regulatory frame work that encourages its development or modify the current regulations to ensure that capture and storage responsibilities are assigned to the actual emitters. In essence, the current environmental policy shall make the oil 
companies to initiate CCS in addition to the biofuels approach designed in National Biofuels Policy of 2007.

\section{Implementation Time}

Implementation of CCS system that can capture desired quantities of greenhouse gases will require sufficient time and planning. Each oil and/or gas formation and power generation facility (medium or large) requires unique method innovations to promote the efficient isolation and capture of $\mathrm{CO}_{2}$ (Amey 2008). Transportation of the gas either by pipelines or ships requires that appropriate technology and equipments are in place and the number of capture facilities fully implemented upon the effective capture costs and cot-sharing agreement finalised between companies and appropriate authorities assigned by the government. In addition to lack of efficient technology suitable for CCS in Nigeria and potential cost inconsistencies, poor planning and implementation policies, unmitigated insecurity in the oil industry and serious corruption problems can shift the project to a longer period. Early compliance by oil and gas companies being the major emitters is another indicator of how shortly and successfully the implementation will be. However, if these problems are adequately addressed CCS project could be executed in the short term, yielding positive results, but this is very difficult.

\section{CONCLUSION}

Carbon Capture and Storage is a carbon emissions reduction process receiving special attention globally today. The technology provides low-carbon approach to use non-renewable fuels like coal or natural gas to ensure security of power supply and is a good opportunity for Enhanced Oil Recovery (EOR) from low producing or partly depleted petroleum formations. Though the current economic situation does not consider the process as financially viable, CCS will play a significant role in mitigating future emissions from developing countries like Nigeria. However, careful approach is required to avoid more problems than benefits. Successful implementation of the technology in Nigeria must be planned ahead of time, effective future agreement is required from the sides of both government and oil companies, policies and strategies shall be base on research findings by environmental, geological and policy analysts couple with lessons from prior developed and developing countries.

\section{ACKNOWLEDGEMENT}

The authors of this article fully acknowledge the effort and contribution of Dr. David Jolley, MSc Hydrocarbon Enterprise Course Director, Geology Department, University of Aberdeen, Scotland United Kingdom.

\section{REFERENCES}

Amey, A. 2008. Carbon, Capture and Storage: The need for a LongerTerm collective Approach. Climate Change Central. URL: http://www.energysolutionsalberta.com/files/attachments/DiscussionPa pers/C3 CCS DiscussionPaper.pdf [Accessed 22-07-2008].

Anderson, S. \& Newell, R. 2003. Prospect for Carbon Capture and Storage Technology: Resources for the Future. Discussion Paper 0268, Washington, DC.

Dooley, J. J.; Dahowski, R. T.; Davidson, C. L.; Wise, M. A.; Gupta, N.; Kim, S. H. \& Malone, E. L. 2006. Carbon dioxide capture and geological storage: A core element of a Global Energy Technology Strategy to address Climate Change. The global Energy Technology Strategy Program GTSP).http://www.pnl.gov/gtsp/docs/ccs report.pdf [12-04-2008].
EIA 2005. Nigeria Country Analysis Brief. Energy Information Administration, April 2005 Pages 1-12. http://www.eia.doe.gov/emeu/cabs/nigeria.html1 [Accessed 30-062008].

EIA 2007. Nigeria Energy Data: EIA International Short Term Energy Outlook, Tables 3a and 3b: http://www.eia.doe.gov/ [ Accessed 22-07200].

Flett, M. A.; Gurton, R.M. \& Taggart, I. J. 2004. Heterogeneous Saline Formations: Long-Term Benefits for geo-sequestration of greenhouse gases. GHGT7: Proceedings of the $7^{\text {th }}$ International conference on Greenhouse Gas Technologies, 5-9 September, 2004, Vancouver, Canada.

GF 2008. How can CO2 be transported once it is capturerd?. Green Facts (GF). Facts on Health and the Environment. http://www.greenfacts.org/en/CO2 capture storage/ [Accessed 25-04200].

Gozalpour, F.; Ren, S. R. \& Tohidi, B. 2005. CO2 EOR and storage in oil reservoirs. Oil and Gas Science and Technology-Rev. TFP, 60(3) 537-546.

Ha-Doung, M. \& Keith, D.W. 2003. Carbon Storage: The economic efficiency of storing $\mathrm{CO}_{2}$ in leaking reservoirs. Clean Technology Environmental Policy, 5:181-189. DOI: 10.1007/SI0098-003-0213-Z.

Heller, J. P. \& Taber, J. J. 1986. Influenced of Reservoir depth on Enhanced Oil Recovery by $\mathrm{CO}_{2}$ flooding. Proceedings of Permian Basin Oil and Gas Recovery Conference of SPE, 13-14 March 1986, Midland, Texas.

Hedriks, C. A.; Wildenborg, A. F. B.; Blok, K.; Floris, F. \& Vanwees, J. D. 2000. Cost of carbon removal by underground storage. Paper presented at the $5^{\text {th }}$ International Conference on Greenhouse Gases Control Technology (GHGT-5), Cairns, Australia, August, 13-16, 2000.

Herzog, H. J. 2001. What Future for Carbon Capture and Sequestration?. Environmental Science and Technology, 35(7):148A153A.

Herzog, H.; Drake, E. \& Adams, E. 1997. CO2 Capture, Reuse, and Storage Technologies for Mitigating Global Climate Change. A white Paper, Final Report. DOE Number:DE-AF22-96PC01257.

Herzog, H. \& Golomb, D. 2004. Carbon capture and storage from Fossil Fuels use. Encyclopaedia of Energy, Volume 1. Article Number: NRGY: 00422. PP 1-11.

IEA 2006. World Energy Outlook 2006. Paris OECD/International Energy Agency (IEA) http://www.eia.org [Accessed 20-07-200].

Ikeme, J. 2008. Assessing the Future of Nigeria's Economy: Ignored Threats from Global Climate Change Debade. Africa Economic Analysis. $\quad$ http://www.afbis.com/analysis/climate change.htm [Accessed 17-07-2008].

IPCC 2007. "Climate Change 2007": Summary for policy makers. The AR4 Synthetic Report. Intergovernmental Panel on Climate Change: Released 17, Nov. 2007, Valencia, Spain. 
Irons, R.; Sekkappan, G.; Panesar, R.; Gibbins, J. \& Lucquiaud, M. 2007. $\mathrm{CO}_{2}$ Capture Ready Plants. International Energy Agency [IEA], Technical study Report Number 2007/4.

Kallbekker, S. \& Torvanger, A. 2004. Can geological carbon storage be competitive? CICERO working paper 2004:05 http://www.cicero.uio.no/media/2735.pdf [Accessed 21-07-2008].

Lewis, C. 2007. Capturing $\mathrm{CO}_{2}$. International Energy Agency (IEA). Greenhouse Gas R\&D Program, May 2007.

Malumfashi, G. I. 2007. Phase-out of gas flaring in Nigeria by 2008. The prospect of a multi-Win project (Review of the Regulatory, Environmental and Socio-Economic Issues). Swiss National Centre for Competence in Research (NCCR), Berne, Switzerland. http://www.nccr.trade.org/ [Accessed 17-07-2008].

Mandil, C. 2005. Legal Aspects of Storing $\mathrm{CO}_{2}$. International Energy Agency [IEA]. Publication Services, 75739, Paris, Codex 15, France.

Rosenzweig, C. \& Casassa, G. 2007. Assessment of observed Changes and Responses in Natural and Managed Sytems. IPCC Forth Assessment Report (AR4). Chapter 1.
Svensson, R.; Odenberger, M.; Johnsson, F. \& Stromberg, L. 2004. Transportation System for $\mathrm{CO}_{2}$-Application to carbon capture and storage. Energy Conservation and Management, 45: 2343-2353.

USGS, 2000. A survey of Geological options for CO2. United Nation Society for Geological Survey. http://www.usgs.gov/ [Accessed 18-05200].

Watson, J.; Mackerron, G.; Ockwell, D. \& Wang, T. 2007. Technology and Carbon Mitigation in developing countries. Are cleaner coal technologies available option?. Fighting climate change. Human solidarity in a dividend world. UNDP Human Development Report, May 2007/16.

Williams, R. H.; Larson, E. D. \& Jin, H. 2006. Synthetic Fuels in a world with high oil and and carbon prices. Paper prepared for $8^{\text {th }}$ International Conference on Greenhouse Gases Control Technologies, Trondheim, Norway, 19-22 June, 2006. 